\section{The acquisition of grammatical morphemes in children with Down's syndrome}

\section{Turid Rutter}

Psychology Undergraduate

\section{Sue Buckley}

\author{
Professor: Developmental Disability \\ Director: Sarah Duffen Centre \\ University of Portsmouth, U.K.
}

\begin{abstract}
The aim of this study was to investigate the acquisition of grammar in children with Down's syndrome, in particular to look at the production of morphological rules (stated by Brown 1973), and onset ages at which they are acquired in their language.
\end{abstract}

In a study of three children in the United States, Brown found that between the ages of 2 and 4 years, typically developing children gradually incorporated a variety of different morphemes in their speech. Although there was little correspondence between the inclusion of separate morphemes and chronological age, there was a strong similarity in relation to the sequence in which the different morphemes appeared in their speech.

In this longitudinal study the children with Down's syndrome produce their first 10 words on average 12 months later than typically developing children, then the majority of the early morphological rules were in fact acquired by the children with Down's syndrome, at a similar rate to typically developing children. This therefore would suggest that once the children with Down's syndrome "get going" with the production of language, they in fact show a similar pattern as typically developing children in the early acquisition of grammar.

\section{Acknowledgement}

The authors wish to thank the parents who collectged the data for the study, which was funded by the Portsmouth Down's Syndrome Trust.

(C) 1993,1999. The Down Syndrome Educational Trust Down Syndrome Research and Practice 1994, 2 (2) 76-82
Introduction

Roger Brown (1973) and colleagues carried out a longitudinal study of the acquisition of grammar in 3 American (typically developing) children, from middle class families. The children were selected from 30 who were initially considered. They were selected primarily because they were all just beginning to speak multi-word utterances, had highly intelligible speech, and were highly voluble (hence easy for data collection), and because the investigators undertaking primary responsibility for each child felt comfortable with the child and the parents.

The principal data of the study are transcriptions of the spontaneous speech of the child with mother at home. For each child at least two hours of transcriptions were obtained every month (for the duration of the study; approximately 2 years).

Brown et al concluded that between the ages of 2 and 4 years, (typically developing) children gradually included a variety of different morphemes in their speech. Although there was little correspondence between the inclusion of separate morphemes and chronological age, there was considerable similarity regarding the sequence in which the different morphemes appeared. Cromer (1981) noted that the order of appearance of morphemes seemed to be governed partly by the complexity of the semantic distinctions which are expressed, and Slobin (1973) noted that the order was governed partly by the complexity of the grammatical rule employed.

Brown studied fourteen morphemes which are obligatory in English. The sequence in which they appeared in the language samples of the three children (Adam, Eve and Sarah) was as follows, approximate ages shown in brackets (Taken from Harris 1990):

1) The present progressive affix on verbs (-ing), denoting an activity in progress - for example, "He's drawing." (19-28 months)

2) The preposition "on" - for example, "Put it on the table." (27-30 months)

3) The preposition "in" - for example, "It's in the cupboard." (27-30 months)

4) The plural/s/ - for example, "Dogs bark." (24-33 months)

5) The irregular past tense of verbs - for example, "It broke", "He ran away", "I made it." (25-46 months)

6) The possessive /s/ - for example, "Tom's book." (26-40 months)

7) The uncontractable copula "be" form (that is, where the "be" form is used with an adjective, preposition or noun phrase and cannot be abbreviated) - for example, "He is." (In response to "Who's there?") (27-39 months)

8) The articles "a" and "the" (counted as separate morphemes.) (28-46 months)

9) Regular past tense forms - for example, "Sally picked a flower." (26-48 months) 
10) The third person singular/s/for present tense verbs - for example, "John rides the bike"; "He likes my dress." (2646 months)

11) Irregular, third-person singular present tense; the verbs "have" and "do" become "has" and "does" for thirdperson sentence subjects - for example, "He has two eyes"; "Mummy does the shopping." (28-50 months)

12) The uncontractable copula "be" form (that is, where the "be" occurs with a main verb and cannot be abbreviated) - for example, "He is." (In response to "Who's coming to the party?") (29-48 months)

13) The contractable copula form (that is, where "be" occurs with an adjective, preposition or noun phrase and where abbreviation is possible) - for example, "They're inside"; "The boy's dirty." (29-49 months)

14) The contractable auxiliary "be" form (that is, where "be" occurs with a main verb and abbreviation is possible) for example, "He's laughing"; "Mummy's cooking dinner." (30-50 months)

The aim of this study was to investigate the acquisition of these grammatical morphemes in the spontaneous speech of children with Down's syndrome.

\section{Method}

At the start of the study the children were all between 12 and 38 months in age, and at the end of the study the children were all between 43 and 67 months in age. They all varied in the stage of language development they were at when the study began, (some were just babbling, others were at the 3 word phrase stage); and in the stage of language development they were at when they left the study.

All of the children involved in the study lived at home. All families volunteered to be included in the project. The primary care-giver (in most cases the mother) was asked to keep accurate diary records of their child's spoken language, and if the child used sign-language, then to record the use and development of this form of communication.

An initial record sheet was sent out on which information was given including child's name, date of birth, and language level so far achieved (including whether being taught to read or sign, and whether the child was at a single word stage, or whether he/she was at a 2, 3 or 4 word phrase level plus detailed information on the actual words already present in the child's language). Following this, record sheets were sent out to each family once a month, consisting of the following:

Record sheet for new words spoken

Record sheet for phrases spoken

Record sheet for words/phrases taught via reading scheme (If reader)

Record sheet for new signs produced (If signer)

The parents were given instructions on how to complete the record sheets. Initially, they were encouraged to record everything the child said, whether it was in imitation or spontaneous. If the child was learning sign-language, the parent was asked to note down the sign that was used, it's meaning, and whether it was an imitation or produced spontaneously. Whether it was directed at someone (this referred to all forms of communication), and the context in which it was produced was also requested.

When the child's language became so copious that it was difficult to record, the parents were asked to choose certain times in the day, e.g. meal-times, in which to sit down with the child and record all that he/she said. Parents were asked to particularly note down new words/signs/phrases that the child produced within the month.

For analysis of the data, certain criteria had to be considered. If these criteria were to be met it must be assumed that a morphological description was an accurate reflection of the child's knowledge, regarding the relationship between combinations of morphemes and the expression of meaning (Brown 1973).

If a simple utterance such as "Daddy gone" occurs in a speech sample, it must be ensured that this does not represent a single morpheme which has been learned by rote in response to comments from adults, such as "Daddy's gone to work", being repeated on different occasions. It can only be considered to be understood when the two morphemes occur either singly ("gone", "daddy") or in combination with other words ("cake gone", "push daddy"). Only then is it possible to identify them as separate morphemes in the child's developing language.

Similarly with plurals, the child who uses "toys" to refer to a group of toys, and also uses the morpheme /s/ when referring to a single toy, clearly does not understand the grammatical concept. Only when this child refers to one toy as "toy" and a group of toys as "toys", can it be assumed that the grammatical rule has been understood.

Thus, when analysing the records, ages of acquisition of morpheme rules were only noted when it was certain that the child had grasped the rule.

In order to calculate the ages of acquisition of the rules in the children from Brown's study, a certain amount of estimation was necessary, due to the arbitrary way in which the ages of acquisition were tabulated. Estimations were, however, minimal.

The children's confidentiality clearly must be ensured, and hence they are referred to under false Christian names.

\section{Results}

The major conclusions drawn from the study were that most children, despite their retardation, acquired the majority of early morpheme rules. The first six rules in the sequence that Brown (1973) described, were also acquired first in the language of the children with Down's syndrome. Of the rules, five were acquired by at least 10 of the 12 children, suggesting that these are the easiest rules for children with Down's syndrome to acquire. On initial viewing, the children with Down's syndrome appeared to acquire rules at a significantly later age (CA) than typically developing children. It was noted, however, that the children with Down's syndrome were also producing their first 10 words at a significantly later age (on average 12 months later than typically developing children). When the delay in onset of first words was considered, it could be suggested that once language "took off" in 
Table 1. The ages at which the morpheme rules were acquired by the 12 children with Down's syndrome in the study. Note how morpheme rule numbers 7, 10 and 12 were never acquired (and not shown). Mean ages also shown on table.

\begin{tabular}{|l|l|l|l|l|l|l|l|l|l|l|l|}
\hline Rule & 1 & 2 & 3 & 4 & 5 & 6 & 8 & 9 & 11 & 13 & 14 \\
\hline Kay & 43 & - & 38 & 36 & 39 & 36 & 45 & 54 & - & 48 & 45 \\
\hline Sarah & 33 & - & - & - & 44 & 40 & 50 & - & - & 48 & 45 \\
\hline Ella & 30 & 28 & 30 & 28 & 28 & 31 & 31 & - & - & - & - \\
\hline Emily & 33 & 32 & 30 & - & 30 & 34 & 34 & 40 & - & 42 & - \\
\hline Maria & 42 & 33 & 42 & 42 & 32 & 34 & 34 & 40 & - & 42 & - \\
\hline Jane & 52 & - & 41 & 50 & 50 & 40 & - & 52 & - & - & - \\
\hline Lisa & $39^{*}$ & $39^{*}$ & - & - & - & $39^{*}$ & 41 & 41 & - & - & - \\
\hline Clare & 43 & 49 & 42 & 42 & 43 & 52 & 43 & 53 & - & 79 & - \\
\hline Ann & - & - & 37 & 49 & 38 & 32 & 37 & - & - & 45 & - \\
\hline Liz & $39^{*}$ & $39^{*}$ & 42 & - & - & 40 & 40 & 46 & 44 & 47 & 44 \\
\hline Peter & 43 & 39 & 41 & - & 41 & 39 & 56 & - & - & - & - \\
\hline Steven & 52 & - & 54 & - & 51 & $49^{*}$ & 53 & - & - & - & - \\
\hline Mean & 40.8 & 37.0 & 39.7 & 41.1 & 39.6 & 38.8 & 41.9 & 47.6 & 44.0 & 51.5 & 44.7 \\
\hline
\end{tabular}

Key to Table 1

* Indicates that these morpheme rules were already in the speech of the child at the beginning of the study, i.e. the actual age of acquisition of rule is unknown, other than it is at this age, or prior to it.

Indicates that the child did not acquire this morpheme in his/ her language.

This table emphasises the fact that most children acquired the majority of the morpheme rules. An important point to note, however, was that rule No. 7, 10 and 12 were acquired by none of the children.

the children with Down's syndrome, they were acquiring the rules at a similar rate to typically developing children.

The ages at which the first six morphemes were acquired were, on initial viewing, rather delayed in comparison with the typically developing children (all data for typically developing children, taken from Brown's study 1973, except onset age of first 10 words, [Brown did not provide such an age in his study] which was taken from research carried out by Katherine Nelson 1973). When the delay in production of first ten words (a mean delay of 12 months) in children with Down's syndrome, was taken into consideration, the picture looked very different. It suggested that the children's rate of acquisition for these morphemes is not as delayed as initially appeared to be the case. When the initial delay was subtracted from the age of acquisition of morphemes, it became apparent that the children were acquiring the majority of morphemes well within the age-range of typically developing children. In some cases, even earlier.

For the purpose of the investigation, it was necessary to obtain a baseline for the age at which typically developing children acquired their first 10 words. For this Katherine Nelson's (1973) work was referred to. She used the measure of the acquisition of the first 10 words in the child's vocabulary, as an indicator of speech onset in preference to other measures, (such as age at first word or number of words at one year): "The very first words are often ambiguous even to parents, and the early course of acquisition may be beset with starts and stops and even regressions. By the time the child has used 10 words, however, speech, although still at an early point, can be said to have begun with certainty." (Nelson 1973). In her study she found the mean age at 10 words for her group was 15.1 months $(S D=1.76)$ (range $=$ 13-19 months). She noted that this agreed with data from other cross-sectional studies.
Table 2. The ages at which the morphemes are acquired by the three non-retarded children cited in Brown's (1973) study. (Taken from Brown 1973, certain amount of estimation of ages was necessary).

The large range in ages at which the rules are acquired should be noted.

\begin{tabular}{|l|l|l|l|l|}
\hline & Adam & Eve & Sarah & $\begin{array}{l}\text { Mean age } \\
\text { (months) }\end{array}$ \\
\hline Rule no. & & & & \\
\hline 1. & 30 & 21 & 35 & 28.7 \\
\hline 2. & 32 & 21 & 35 & 29.3 \\
\hline 3. & 31 & 23 & 35 & 29.7 \\
\hline 4. & 32 & 25 & 34 & 30.3 \\
\hline 5. & 35 & 28 & 35 & 32.7 \\
\hline 6. & 39 & 25 & 36 & 33.3 \\
\hline 7. & 35 & 27 & 38 & 33.3 \\
\hline 8. & 38 & 29 & 39 & 35.3 \\
\hline 9. & 43 & 26 & 48 & 39.0 \\
\hline 10. & 42 & 30 & 45 & 39.0 \\
\hline 11. & 39 & 31 & 50 & 40.0 \\
\hline 12. & 44 & 32 & 49 & 41.7 \\
\hline 13. & 45 & 33 & 50 & 42.7 \\
\hline 14. & 46 & 34 & 50 & 43.3 \\
\hline
\end{tabular}


Table 3. The comparison between ages and ranges at which typically developing children and children with Down's syndrome acquire the morpheme rules.

\begin{tabular}{|l|l|l|l|l|}
\hline & $\begin{array}{l}\text { Mean age } \\
\text { TD }\end{array}$ & $\begin{array}{l}\text { Mean age } \\
\text { DS }\end{array}$ & $\begin{array}{l}\text { Range } \\
\text { TD }\end{array}$ & $\begin{array}{l}\text { Range } \\
\text { DS }\end{array}$ \\
\hline Rule no. & & & & \\
\hline 1 & 28.7 & 40.8 & $21-35$ & $30-52$ \\
\hline 2 & 29.3 & 37.0 & $21-35$ & $28-49$ \\
\hline 3 & 29.7 & 39.7 & $23-35$ & $30-54$ \\
\hline 4 & 30.3 & 41.2 & $25-34$ & $28-50$ \\
\hline 5 & 32.7 & 39.6 & $28-35$ & $28-51$ \\
\hline 6 & 33.3 & 38.8 & $25-39$ & $31-52$ \\
\hline 7 & 33.3 & ------- & $27-38$ & ------- \\
\hline 8 & 35.3 & 41.1 & $29-39$ & $31-56$ \\
\hline 9 & 39.0 & 47.7 & $26-48$ & $40-54$ \\
\hline 10 & 39.0 & ------- & $30-45$ & ------- \\
\hline 11 & 40.0 & 44.0 & $31-50$ & $44-44$ \\
\hline 12 & 41.7 & ------- & $32-49$ & ------- \\
\hline 13 & 42.7 & 51.5 & $33-50$ & $42-79$ \\
\hline 14 & 43.3 & 44.7 & $34-50$ & $44-45$ \\
\hline
\end{tabular}

Key $\quad \mathrm{TD}=$ Typically developing children DS $=$ Children with Down's syndrome

The high standard deviation values should be noted, indicating large ranges for both children with Down's syndrome and typically developing children. On initial viewing, it appears that the children with Down's syndrome are indeed rather delayed in acquiring the morpheme rules, in comparison with typically developing children.
Table 4. The number of children (out of the 12 in the study) who acquire the morpheme rules.

Interesting point to note is how 3 of the rules were not acquired by any of the children with Down's syndrome.

\begin{tabular}{|l|l|}
\hline Morpheme rule & $\begin{array}{l}\text { No. } \\
\text { children }\end{array}$ \\
\hline 1. Present progressive & 11 \\
\hline 2. Preposition "on" & 7 \\
\hline 3. Preposition "in" & 10 \\
\hline 4. Plural /s/ & 6 \\
\hline 5. Irregular past tense & 10 \\
\hline 6. Possessive /s/ & 12 \\
\hline $\begin{array}{l}\text { 7. Uncontractable copula "be" } \\
\text { form }\end{array}$ & 0 \\
\hline 8. Articles "a" and "the" & 11 \\
\hline 9. Regular past tense & 6 \\
\hline 10. Third person singular & 0 \\
\hline $\begin{array}{l}\text { 11. Irregular third person singular } \\
\text { present tense }\end{array}$ & 1 \\
\hline $\begin{array}{l}\text { 12. Uncontractable auxiliary "be" } \\
\text { form }\end{array}$ & 0 \\
\hline $\begin{array}{l}\text { 13. Contractable copula "be" } \\
\text { form }\end{array}$ & 6 \\
\hline $\begin{array}{l}\text { 14. Contractable auxiliary "be" } \\
\text { form }\end{array}$ & 3 \\
\hline
\end{tabular}

Having obtained a baseline for the age that typically developing children acquire their first 10 words, it was necessary to do the same with the sample of children with Down's syndrome. We searched through the records not only of the children that had been chosen for detailed analysis in our study, but also the records of the other 30 or so children that had, for one reason or another, not been included in the analysis. Eventually data was acquired on the first words of nine children. The mean age at which they acquired 10 words was found to be 27 months, $(S D=7)$ (range $=20-38$ months). This is 12 months behind the mean age at which typically developing children apparently acquire their first 10 words; a significant delay (supporting Rondal, 1988 and Gunn, 1985).

Unlike Brown and numerous other researchers, mean length of utterance (MLU) was not used for comparison, since Miller's (1987) view was accepted, that using MLU ignores the fact that children's comprehension abilities show substantial change while they are at the no-word stage of language production (Benedict 1979; Miller et al 1980). Using MLU would mean that one was assuming similar comprehension development based on production ability, an assumption that is not warranted in persons with mental retardation. As Miller (1987) pointed out, the one-word period of development extends through most of the second year of life. Matching at this level opposes Brown's (1973) logic for using MLU, that is, as an index of structural development. Hence chronological age (CA) of the children will be used.

The overall picture obtained from the results of the study shall be considered, i.e., the mean ages at which the various morpheme rules are acquired, and the sequence in which they are acquired, as this was what Brown commented on as being remarkably constant in typically developing children. Then an overview of the language levels achieved by each child shall be considered, along with the different morphemes that are. or are not acquired in his or her spoken language. This will ensure that the individual differences are made quite clear, as to look at the means only, would provide a very biased picture.

When considering the means, the sequence in which they appear in speech is not the same as found by Brown. The first six morphemes that Brown identified did also occur as the 
Table 5. The comparison between the mean ages of acquisition of morpheme rules in children with Down's syndrome and typically developing children (considering the delay in onset of first 10 words, in children with Down's syndrome, of 12 months).

\begin{tabular}{|l|l|l|l|}
\hline & $\begin{array}{l}\text { Mean age } \\
\text { DS }\end{array}$ & $\begin{array}{l}\text { Mean age DS } \\
\text { (minus 12 months) }\end{array}$ & Mean age TD \\
\hline Rule no. & & & \\
\hline 1. & 40.8 & 28.8 & 28.7 \\
\hline 2. & 37.0 & 25.0 & 29.3 \\
\hline 3. & 39.7 & 27.7 & 29.7 \\
\hline 4. & 41.2 & 29.2 & 30.3 \\
\hline 5. & 39.6 & 27.6 & 32.7 \\
\hline 6. & 38.8 & 26.8 & 33.3 \\
\hline 7. & ------- & ------- & 33.3 \\
\hline 8. & 41.9 & 29.9 & 35.3 \\
\hline 9. & 47.7 & 35.7 & 39.0 \\
\hline 10. & ------ & ------ & 39.0 \\
\hline 11. & 44.0 & 32.0 & 40.0 \\
\hline 12. & ------- & ------- & 41.7 \\
\hline 13. & 51.5 & 39.5 & 42.7 \\
\hline 14. & 44.7 & 32.7 & 43.3 \\
\hline
\end{tabular}

Key to Table 5:

TD = Typically developing

DS = Children with Down syndrome

This table clearly identifies how, when the delay in onset of acquisition of first ten words is taken into consideration, it appears that the children with Down's syndrome are not in fact very delayed in relation to typically developing children and acquisition ages of morpheme rules. In several cases, they appear to acquire the rules ahead of the mean age in typically developing children.

first 6 rules to be acquired in the children with Down's syndrome, though not in the same order.

In the children with Down's syndrome, the rules were acquired all within a short period of time (on average), with only 4 months between the acquisition of the first (the preposition "on") and the sixth (the plural /s/). The seventh morpheme that Brown identified as appearing in the language of typically developing children (the uncontractable copula "be" form) did not occur at all in the speech of the children in our study. This is not to say that it would never occur in the speech of such children.

Brown's eighth morpheme (articles "a" and "the") occurred as the seventh in the sequence from our results. It appeared at almost exactly the same (mean) age as the sixth (plural /s/) to be acquired in the children with Down's syndrome. The ninth morpheme to be acquired by the children with Down's syndrome in this study was the fourteenth to be produced in Brown's study (the contractable auxiliary "be" form). It should be noted, however, that only three children acquired this rule. The morphemes occurred at virtually the same mean age in the population with Down's syndrome (less than a month between their acquisitions ages).

The tenth rule acquired by the children with Down's syndrome was Brown's ninth rule (regular past tense forms), acquired on average, 3 months after the previous one. The final rule acquired by the children with Down's syndrome was Brown's thirteenth rule (the contractable copula "be" form). There was a mean gap of 4 months between the acquisition of this rule and the previous (tenth) one.

Thus, Brown's seventh, tenth and twelfth morphemes were acquired by none of the children in our study. These rules were: The uncontractable "be" form, the third-person singular/s/ for present tense verbs, and the uncontractable auxiliary "be" form. Brown's eleventh rule, the irregular third-person singular present tense ("has" and "do"), was only acquired by one of the children in the study, and the fourteenth rule, the contractable auxiliary "be" form was only acquired by three children.

It seems rather surprising that out of a sample of 12 children, that none of them achieved these three morpheme rules. Suggestions as to why this occurred can only be speculative. It is surprising that both of the "uncontractable forms" were never acquired. An example of rule 7 , the uncontractable copula "be" form is where the "be" form is used with an adjective, preposition or noun phrase and cannot be abbreviated - for example, "He is." (in response to "Who's there?") (From Brown, cited in Harris 1990). An example of the uncontractable auxiliary "be" form, is where the "be" occurs with a main verb and cannot be abbreviated - for example, "He is." (in response to "Who's coming to the party?") (Brown, cited in Harris 1990).

Perhaps there is some conceptual leap in understanding and producing such forms of grammar which children with Down's syndrome are unable to acquire. This study did not look into comprehension, however this aspect should be investigated, since in typically developing children, Benedict (1979) found evidence supporting the view that comprehension precedes production by 5 months. Holdgrafer (1981, 1982), however, claimed that language can develop independently in comprehension and production, in children with Down's syndrome. If these children can comprehend these rules when they are used in speech directed at them, then perhaps they could be taught production of them.

Perhaps the reason for the lack of these rules in the speech of these children, is associated with the type of speech the care-givers direct at the child. Maybe the mothers use a more directive style of speech, with less questioning, and so the children simply do not have the opportunity in which to pick up such grammar rules. As Nelson (1973) states, directive or intrusive aspects of a mother's language seem to influence the child's first words. Later, according to New- 
port et al (1977), aspects of her questioning seem to influence the child's acquisition of syntactic elements.

Peterson and Sherrod (1982) found that as children's MLU increased, the mothers were becoming more discriminating and more demanding concerning their children's speech.

Petersen and Sherrod (1982) noted that mothers of children with Down's syndrome used more semantically unrelated child-directed speech than did the mothers of typically developing children. Furthermore, mothers of children with Down's syndrome tended to use an even greater proportion of unrelated speech with the higher MLU children than with the lower MLU children. This pattern is opposite to that seen with the group of typically developing children whose mothers used less unrelated speech with high MLU children. In relation to our study, most of the children were eventually producing sentences of 3 or 4 combined words, a couple of the children were producing longer sentences. However, in the children that were producing short MLU's, perhaps the mothers were using more unrelated speech, in which case, maybe they had less opportunity for imitation of relevant aspects of grammar.

Perhaps the mothers never gave the children the opportunity to produce sentences that would include these aspects of grammar. Perhaps, they expected the children to only understand simple grammar, and so consequently they spoke to them in simpler "key-word" sentences, and hence reduced the chance for the children to imitate such speech.

It should be noted, that some of the children were producing fairly long and complex sentences. Had all of the children been producing short, simple sentences, then it could be suggested that perhaps the more complex grammar rules seem to be acquired as the child's MLU increases. However, as stated, this is unlikely to be the case. Larger numbers of children need to be studied to investigate this further. In Brown's study, all of the rules were acquired by the stage $M L U=4$ was reached (or at that stage, in Sarah's case).

The fact that the irregular third person singular present tense (rule 11) was acquired by one child, (Liz) indicates that it is unlikely to be conceptually too difficult for children with Down's syndrome to acquire. The same can be applied to the contractable auxiliary "be" form (rule 14), only three children acquired this rule. This implies, however, that it is clearly possible to teach this to children with Down's syndrome. What must be worked out, is what was different in the teaching of these children, that allowed them to acquire this morpheme rule. Perhaps a close look at maternal language in such cases would provide a hint as to how to go about teaching such rules to the other children.

For future research, it would be of great interest to set up an experimental situation, with groups of children receiving different forms of teaching of grammar. For example, reading could be employed as an aid in this field. Perhaps, having taught children the basics of reading, children could be given flash-cards with printed responses to whole questions. For example, a picture of a clown could be shown to the child. The mother could ask the child "what is he doing?", and there could be a choice of flash-cards for the child to choose from, for example with one saying "he's crying" and one saying "he's laughing". Attempts could be made at teaching various forms of grammatical rule to children via this method. Simply allowing the child to become familiar with the sound of the words in that format, may encourage usage of such rules in their own speech.

The question is, why do most of the children master the majority of the rules, and others achieve only a few? Two of the children (Steven and Lisa) only achieve 5 of the rules all together. Of the five that they do acquire, they both acquired the present progressive affix on verbs (rule 1), the possessive /s/ (rule 6), and the articles "a" and "the" (rule 8). It was interesting to note that all of the children acquired the possessive /s/. Presumably this is conceptually simple for children with Down's syndrome (as well as typically developing children) to acquire.

The fact that all of the standard deviations are so high (bar the fourteenth rule, however, it should be noted that only three children acquired this rule), gives clear indication that great care must be taken not to dwell on mean values as they could lead to incorrect conclusions being drawn. The importance of individual differences cannot be over-emphasised. It should be accepted that as in typically developing children, there are large variations in the ages of acquisition, Brown himself points this out. The points of great importance seem to be that considering these variations in ages of acquisition, that when the children start to "get going" on their speech, they appear to pick up very quickly.

Fowler (1990) claimed that on the whole individuals with Down's syndrome fail to move beyond the "most rudimentary stages of syntactic development". Our study clearly shows that most of the children were not in fact limited merely to "rudimentary" speech. The fact that each of the morpheme rules (bar three) were acquired by at least one child, seems to indicate that it is likely that given appropriate training, some of the other children would also be able to master the rules. It illustrates that the rules are not conceptually unobtainable by such children.

One way to look at the acquisition of these morphemes is perhaps to consider which of them were acquired by how many of the children, this should clarify the frequency in which they were achieved (see table 4).

This shows clearly that, except for rule 7 , the first 9 rules are fairly consistently acquired by the children (see table 4). From this overview, it is quite clear that it is the rules that are learnt at the more advanced ages in typically developing children, that are also clearly considered more complex by the children with Down's syndrome. So much so that only a few of the children seem to acquire them, (within this study at any rate).

Brown's sixth rule, the possessive /s/ was acquired by all twelve of the children, the standard deviation was however high $(S D=6.35)$. The range was 31-52 months. Ten of the 12 children acquired the rule at below 40 months, and so looking at the mean, really does distort the picture. The range for typically developing children to acquire this rule is 25-39 months, and so it is clear that the majority of the children do indeed acquire it within a typical time-span.

Eleven of the children acquired the present progressive (ing, rule 1), and the articles ("a" and "the", rule 8). It was surprising that Ann did not acquire the present progressive, admittedly she only acquired 6 of the 12 rules, however, the 
ones that she did acquire were achieved at relatively early ages. It should be considered, however, that she left the study at 50 months, and hence any improvements in grammar beyond this age were not recorded.

With regard to future research, to remedy that, a better way of keeping record of a child's language acquisition would be (as Brown (1973) and his colleagues did) to visit the child for a fixed period each week or so, and record (on tape and in writing) the child's language, noting context and the mother's verbal interactions. There are, however, drawbacks to that method as well. For example, the child would therefore be in a rather false setting since there would be a relative stranger there (clearly the child would get used to his/her presence, given time). Also, if there is only a fixed period of, for example, one hour per week, then, only a limited amount of speech can be recorded (at least, only a limited vocabulary, since during one hour, not that many topics would be touched upon). Brown, however, did state that so much data was collected in the play sessions they had with their children, that there was almost too much data.

Whereas a speech sample may make it possible to identify separate morphemes positively, the absence of examples of such grammar rules, does not lead unequivocally to the conclusion that the child is not able to distinguish specific morphemes. It is possible that the opportunity for making a specific distinction did not occur within the period during which the child's speech was sampled. This problem can never be completely avoided, however, the difficulties it presents can be considerably reduced by basing morphemic descriptions on large samples of speech - usually 100 utterances - and, whenever possible, taking account of the relationship between the child's utterances and the context in which they are employed. This should be taken account of for future research.

In the case of collecting linguistic data on children with Down's syndrome, due to the particular problems the children have with articulation and pronunciation, it is beneficial to have the mother to keep the records, as she will be far more likely to understand what the child is intending to say. That can also be a problem, however, in that it is possible that the mother may overcompensate for the child and in effect "put words into his/her mouth" i.e., write down more than the child is actually saying e.g. child actually says "pick m'up", mother writes "pick me up". It is difficult to know, but perhaps the child has not in fact grasped the concept of the word "me", and thinks "me up" is in fact just one word meaning "up". The only way this can be clarified is if the word "me" is used singularly and in conjunction with some other word. Clearly this is how, when working out if grammatical rules were applied accurately, it was checked, i.e., whether the rule was used elsewhere.

If the mothers had known what the aim of this research project, i.e., that grammar acquisition was being studied, then perhaps they would have looked more specifically for such examples in their child's speech. On the other hand, had the mothers known, perhaps they would unconsciously have imagined that the child had produced such grammar forms.

\section{References}

Benedict,H. (1979). Early lexical development - Comprehension and production. Journal of Cild Language. 6. 183200.

Brown,R. A First Language. Allen \& Unwin Ltd.

Cromer,R. (1981). The development of language and cognition: The cognitive hypothesis. In Foss,B. (Ed.). New Perspectives in Child Development. Harmondsworth: Penguin. Fowler, A. (1990). Language abilities in children with Down syndrome. Evidence for a syntactic delay. In Ciccetti, D. \& Beeghly, M. Children with Down Syndrome: A Developmental Perspective. Cambridge University Press.

Gunn,P. (1985). Speech and language. In Lane,D. \& Stratford,B. Current Approaches to Down Syndrome. Holt, Rinehart \& Winston.

Harris,J. (1990). Early Language Development. Routledge. Holdgrafer,G. (1981). Mode relations in language learning by language-deficient retarded subjects. Perceptual and Motor Skills, 53, 520-523.

Holdgrafer,G. (1982). Teaching comprehension and production. Perceptual and Motor Skills. 55. 306.

Miller,J. (1987). Language and communication characteristics of children with Down syndrome. In Pueschel,S., Tingey,C., Rynders,J., Crocker,A. \& Crutcher,D. (Eds.).New Perspectives in Down Syndrome. Brookes Publishing Company.

Nelson,K. (1973). Structure and strategy in learning to talk (serial No. 149). Society for Research in Child Development Monographs. Nos. 1-2. Vol.38.

Newport,E.I., Gleitman,H. \& Gleitman,L. (1977). Mother l'd rather do it myself: Some effects and non-effects of maternal speech style. In Snow,C.E. \& Ferguson,C.A. (Eds.). Talking to Children: Language Input and Acquisition. Cambridge: Cambridge University Press.

Peterson,G. \& Sherrod,K. (1982). Relationship of maternal language to language development and language delay of children. American Journal of Mental Deficiency, 86, 391398.

Rondal,J. (1988). Language development in Down's syndrome: A life span perspective. International Journal of Behaviour Development. 11 (1) 21-36.

Slobin, D. (1973). Cognitive Prerequisites for the Development of Grammar. In Ferguson,C. \& Slobin,D. (Eds.).Studies of Child and Language Development. New York: Holt, Rinehart \& Winston. 